\title{
Research on the High-Tech Enterprise Performance Index System
}

\author{
Lan Fu', Rong Fu \\ ${ }^{1}$ Statistics School, Jiangxi University of Finance of Economics, Nanchang, China \\ ${ }^{2}$ Nanchang Liquefied Petroleum Gas Company, Nanchang, China \\ Email: fulan60010068@sina.com, furong0830@hotmail.com
}

Received January 2014

\begin{abstract}
The purpose of this essay is to design a framework of a performance system which is subject to the characteristics of China high-tech enterprises. It is based on analyzing the principles and significance of the performance system of high-tech enterprises. The framework will promote the standardization management of high-tech enterprises of China.
\end{abstract}

Keywords

The High-Tech Enterprise; Performance; Index System

\section{The Significance of a High-Tech Enterprise's Performance}

\subsection{Recognized Principles and Basis of a High-Tech Enterprise.}

There is no clear conclusion concerning the definition of the high-tech enterprise. However, people can obtain the identified principles and basis of a high-tech enterprise based on the operation of the relevant documents and the relevant departments of government.

\subsubsection{The Recognized Principles of a High-Tech Enterprise}

1) The loose principle. At present, the ministries and commissions of the State Council, the institution of financial regulatory and local council has a different standard on the recognized of a high-tech enterprise. For instance, the High-Tech Ministry, the Financial Ministry and the State Administration of Taxation issued "Recognition of management methods concerning the high-tech enterprise". While the China Banking Regulatory Commission (CBRC) and the High-Tech Ministry jointly released "Guidance on further increase of SME credit support”. Therefore, for the recognition of a high-tech enterprise, it should take the appropriate loose principles instead of narrow principles and cover all tech SMEs and micro-enterprises [1].

2) The low-cost principle. For the recognition of a high-tech enterprise, the identification of cost should be considered. In addition, it should try to reduce the recognition of cost. Thus, the requirements of a recognized standard should not be too complex, and the identified process should not be overly inconvenient. Briefly, the recognized standard should be as simple as possible, easy operation and implementation. 


\subsubsection{The Recognized Bases of Technological Enterprises}

In light of the loose and low-cost principles, a high-tech enterprise can be recognized if it can meet one of the following conditions:

A. enterprise has been identified as high-tech enterprises;

B. private high-tech enterprise has been registered in the Provincial Science and High-Tech Department;

C. enterprise has implemented a municipal or maniple above the high-tech project in the past three years;

D. enterprise implements patent technique or independent proprietary intellectual rights.

\subsection{The Importance of a High-Tech Enterprise's Performance}

The essence of performance is a measure of management and control. It provides a reference to managers by the comparison of an occurred result and a pre-determined criterion before they take a further step. Firstly, correct performance for high-tech companies can assist investors to correctly understand the high-tech enterprises. Secondly, it makes the incentives function properly [2]. Furthermore, management methods and process innovation of high-tech enterprises benefit from it.

However, enterprise production and management capabilities, process and results can be reflected through a number of financial indicators and innovation ability index. According to the characteristics of technological enterprise, its performance indicates the reality of the profitability and future growth and development potential. Therefore, constructing a comprehensive scientific index system has become an important part of the performance of the technological enterprises.

\subsection{The Characteristics of Technological Enterprises}

\subsubsection{Enterprises with a Flexible Organizational Structure}

The flexibility of its organizational structure is mainly reflected in two aspects. On the one hand, companies can adjust the setting of the business functions in terms of the changes of the market. On the other hand, employees can internally flow at any time according to the changes of the business. This flexibility allows the entire organization in a flexible flow state, able to change with the external market fluctuations.

\subsubsection{Enterprises have Employees with a Strong Sense of Innovation and Innovative Capacity}

The employees in the enterprise are initiative and knowledge-based. They possess the knowledge and skills of the enterprise, the comprehensive judgment and decision-making ability, and are subject to full authorization and incentive to work independently.

\subsubsection{Speeding up the Product and Service Innovation of Enterprises.}

Faced with the rapid changes in the environment, the enterprise provides products and services to the market through the continuous, comprehensive and collaborative innovation faster than the competition to meet customer needs, thus gaining an advantage in the market competition.

\subsubsection{Production by Standardized Transition to the Non-Standardized.}

Enterprises should pay more attention to the market demand for differentiation and the characteristics of individual consumers. In addition, enterprise can adopt a non-standardized production according to customer demand. Meanwhile, it utilizes small quantity and variety of production to replace the large quantities and single product of traditional enterprises. Finally, high-tech enterprises obtain business growth through emphasizing innovation.

\section{The Principles of Constructing a High-Tech Enterprise Performance System}

\subsection{The Principle of Objective and Impartial}

The inputs and outputs of the process of the high-tech enterprises are extremely complex and difficult to understand. This leads to the performance very prone to subjective bias, which provides an opportunity to meet the different purposes of the evaluators. Therefore, in the corporate performance, the evaluator must be judged aloof and independent stance and exquisite competent. In order to reduce the influence of artificial factors of enterprise performance, enterprise should evaluate pros and cons objective stance, a fair attitude evaluate gains and losses, reasonable way to measure corporate performance. 


\subsection{Scientific and Rational Principles}

The design of an effective performance system must reflect the unique characteristics of the enterprise. Performance system can follow the traditional performance system in some of the indicators of high-tech enterprises, with its own characteristics, taking into account the scientific development of a number of other indicators. The relationship between the profit targets of enterprise and high-tech enterprises in the research and development process, innovation, knowledge assets contribution is vague and difficult to quantify. Consequently, scientific and reasonable method should be used to evaluate these aspects.

\subsection{Condensed Applicable Principles}

Traditional performance in the assessment of technological enterprise performance is too one-sided and simplistic. Thus, it is easy to distort the true performance of the high-tech enterprises. However, if in constructing high-tech enterprise performance system in the face mask to work out the many profound and sophisticated indicators, the evaluators will inevitably lead to a loss. So we must seize the technological characteristics of enterprises to identify the essential things to work out some key indicators operability. Otherwise, the performance system cannot be members agree, accepted by the organization members. This situation will lead to organization members ignore its existence or less reluctant to comply with. Such information provided may be inaccurate, untimely and not objective. Therefore, a good performance system must be as required according to the user's heart design.

\subsection{The Principles of Service Goals}

The purpose of the business existence is to obtain the profit, which represents the efforts of enterprise on the profitability of the corporate research and development activities, production and business activities, marketing activities and other aspects. Enterprise performance should also serve the aims of enterprises and contribute to the profitability of enterprises. Enterprise Performance can find some of the problems that hinder the profitability of the business by the key factors affecting the profitability of the business. Then it can provide timely and detailed information for managers operating decisions.

\section{High-Tech Enterprise Performance Index System}

Before you begin to format your paper, first write and save the content as a separate text file. Keep your text and graphic files separate until after the text has been formatted and styled. Do not use hard tabs, and limit use of hard returns to only one return at the end of a paragraph. Do not add any kind of pagination anywhere in the paper. Do not number text heads - the template will do that for you.

Finally, complete content and organizational editing before formatting. Please take note of the following items when proofreading spelling and grammar:

\subsection{The High-Tech Enterprise Performance of Design}

From the above analysis, constructing a high-tech enterprise performance index system should not only consider the profitability of the enterprise but also to consider the growth and development potential of high-tech enterprise. However, growth and development potential of an enterprise depends primarily on the intellectual capital of the enterprise. Therefore, high-tech enterprise performance system should include two aspects. One is to reflect the profitability of the financial indicators. Another one is to reflect the innovation ability index of business growth and future development potential. This essay designed a high-tech enterprise performance index system. As shown in Figure 1.

\subsection{Interpretation of Indicators and Data Sources}

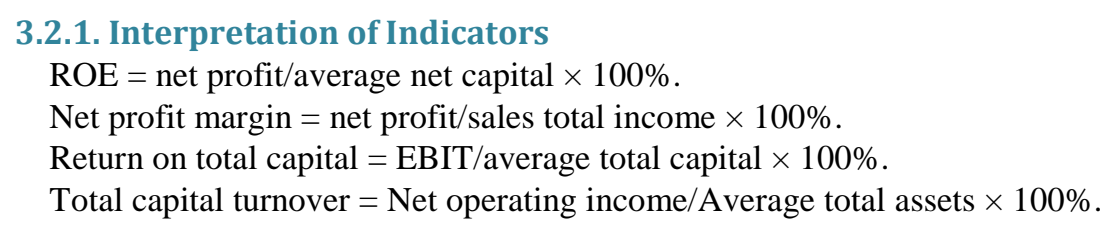




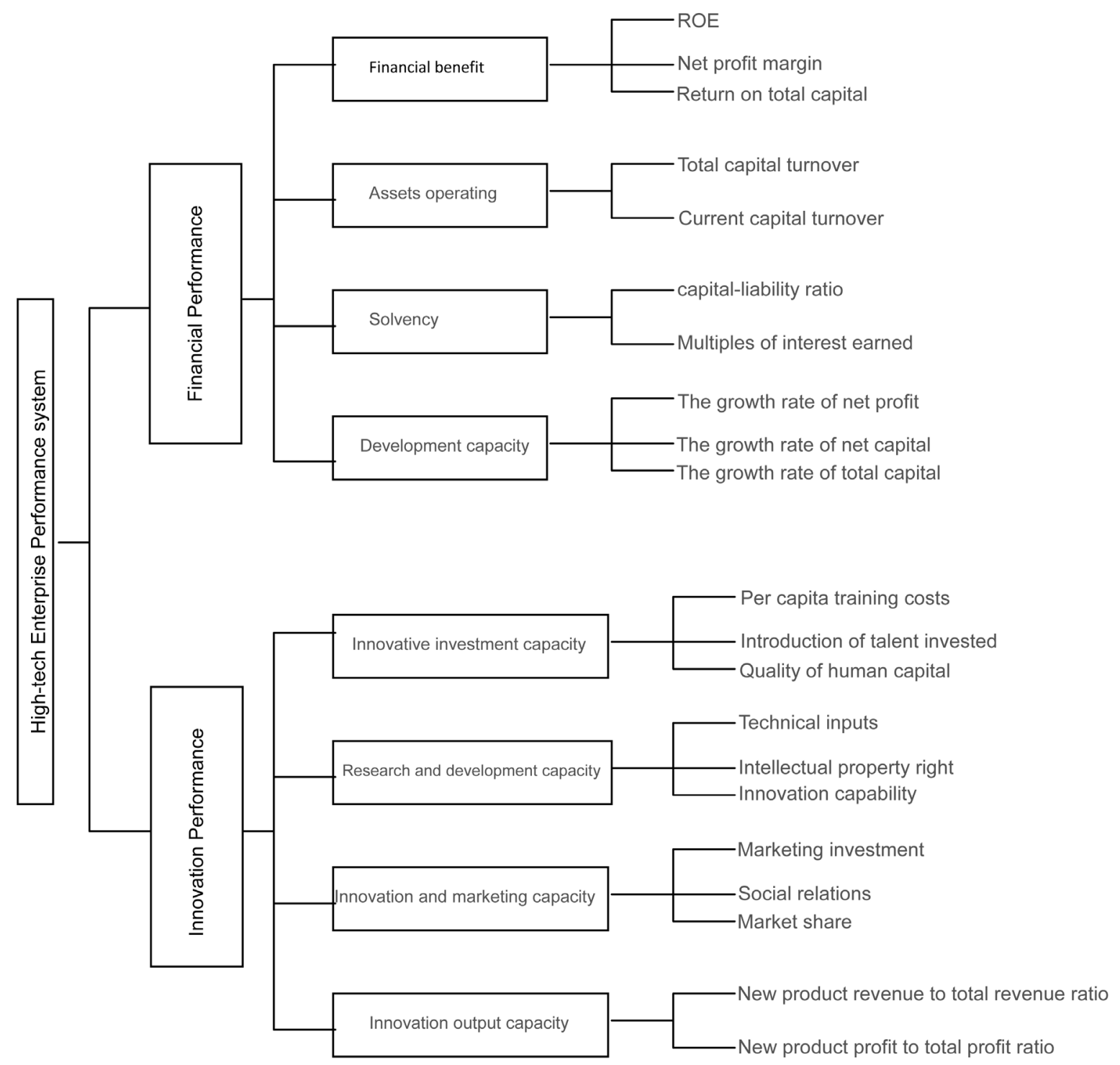

Figure 1. High-tech enterprise performance system.

Current capital turnover $=$ the main net operating income/Average total current assets $\times 100 \%$.

Capital-liability ratio $=$ Total liabilities/total assets $\times 100 \%$.

Multiples of interest earned $=$ EBIT/interest expense.

The growth rate of net profit $=$ (base period sales - sales of the reporting period)/sales of the reporting period

The growth rate of net capital $=$ (base period net assets - net assets of the reporting period) $)$ net assets of the reporting period $\times 100 \%$.

The growth rate of total capital $=$ (base period total assets - total assets of the reporting period $) /$ reporting period, the total assets $\times 100 \%$.

Per capita training costs $=$ annual training costs/sales revenue $\times 100 \%$.

Introduction of talent invested $=$ annual talent reference funds/sales revenue $\times 100 \%$.

Quality of human capital $=$ with college or higher staff/number of employees $\times 100 \%$.

Technical inputs $=\mathrm{R} \& \mathrm{D}$ expenses/total sales $\times 100 \%$.

Intellectual Property right $=$ the number of corporate patent owners.

Innovation capability $=$ new product to market/the total number of products developed $\times 100 \%$.

Marketing investment $=$ sales investment/sales revenue $\times 100 \%$.

Social relations $=$ bank corporate credit rating (good, general, poor). 
Market share $=$ dominant product sales revenue/the same industry product revenue $\times 100 \%$.

New product revenue to total revenue ratio $=$ new product revenue/total revenue $\times 100 \%$.

New product profit to total profit ratio $=$ profit/total profits $\times 100 \%$.

\subsubsection{Sample Selection and Data Collection Methods Recommended}

The paper selected the range of samples from the province science and high-tech enterprises. The sample data is from a table statistics of the Provincial Bureau of Statistics, industrial enterprises, financial statements, and annual report data. This involves multiple industries, the pharmaceutical industry, mechanical industry, electronics and communications industry, with full representation.

\section{High-Tech Enterprise Performance Method Selection}

In order to reflect the performance of high-tech enterprises effectively, enterprises could choose a method which can quantify the impact factors of performance. This is the purpose of selection of the performance method. The method is not based on objective methods of expert judgment. Thus, it can remove the interference of artificial factors, and demonstrate the objectivity and fairness. In addition, high-tech enterprises with high input, complex performance, covering a wide range of indicators reflect different aspects of the performance situation of enterprises, but in a way larger principal component analysis can simplify complex problems, an effective solution to this problem. Moreover, from the sample size, the method can ensure that the number of samples is far more than the number of indicators, which meet the basic requirements of the principal component analysis. Finally, principal component analysis is in line with the characteristics and the development of high-tech enterprises influencing factors to adapt its complex characteristics [3].

Principal component analysis is a method for dealing with multi-information. The principle of the method is to refine a few unrelated composite indicators from the multiple interrelated indicators. In other words, it extracts important information from the original wealth of information. Then it composes a new composite indicator. Meanwhile, these indicators can fully express the original information to simplify the index purposes on the basis of loss or less loss.

Principal component analysis is based on the data itself and is an objective of the weighting method. It is in terms of the embodied values on the indicators of the actual observations, and analysis of the internal structure of the relationship between the various indicators, accurate exclude irrelevant indicators, so as to ensure the objectivity of the results based on maximizing the process simple, fair, objective of the performance. Different stakeholders have a great difference in attention for each indicator. However, the principal component analysis can simplify information properly. Therefore, this method is a good way to coordinate the above problems.

In summary, this essay indicates the unique characteristics of high-tech enterprises and adopts the principal component analysis to assess the performance of the high-tech enterprises. It also combines the financial indicators and innovation indicators through analyzing a few new variables which transform from the original number of variables. However, the basic information of the original variables still remains. According to the data itself to get the weighting of indicators in a comprehensive performance, obtained results are more objective and fair.

\section{References}

[1] Men, X.C. (2003) Growth of Venture Capital and High-Tech Enterprises. Southwestern University of Finance and Economics Press.

[2] Micro, F. (2001) Intellectual Capital Index System of Industrial Engineering and Management. 1.

[3] (2006) Orchestration High-Tech Enterprises, Market-Oriented Strategy and Strategic Performance Study. Scientific Management Research Study, 6. 